\title{
Miosite dos músculos mastigatórios em cão da Raça Shar-Pei: relato de caso
}

\section{Masticatory muscle myositis in Shar-Pei dog: case report}

\author{
Thalita Priscila da Silva Peres, ${ }^{*}$ Rita de Cássia da Silva Machado Neves, ${ }^{* *}$ Waldenir Correia do Nascimento, ${ }^{* * *}$ \\ Gentil Ferreira Gonçalves, ${ }^{* \star *}$ Edson Moleta Colodel, ${ }^{* \star * \star *}$ Valéria Régia Franco Sousa****
}

\begin{abstract}
Resumo
A miosite eosinofílica é uma doença imunomediada que acomete cães e caracteriza-se pela produção de anticorpos direcionados contra as fibras que constituem os músculos responsáveis pela mastigação. Esse distúrbio apresenta-se nas formas aguda ou crônica. A aguda é a mais comumente encontrada e envolve pseudotrismo, podendo progredir até a impossibilidade da abertura bucal. A forma crônica se caracteriza por atrofia e necrose dos músculos mastigatórios. A dosagem sérica de creatina quinase (CK) e o exame histopatológico do músculo envolvido são importantes para estabelecer o diagnóstico e avaliar a eficácia no tratamento realizado. A resposta à terapia e o prognóstico mostram-se melhores quando a doença é tratada em sua forma aguda. Este artigo relata um caso de miosite dos músculos mastigatórios em um canino, fêmea, da raça Shar-Pei, atendido e tratado no Hospital Veterinário da Universidade Federal de Mato Grosso (HOVET/UFMT), com curso de cinco meses. A CK apresentavase elevada e ao exame histopatológico constatou-se necrose coagulativa, multifocal moderada de fibras musculares, infiltrado perivascular composto por células fagocíticas e frequente regeneração muscular. O animal foi tratado com prednisona (2 mg/kg), uma vez ao dia (SID), durante 20 dias consecutivos e apresentou melhora considerável. Conclui-se que a miosite dos músculos mastigatórios do animal em questão era de caráter imunológico e respondeu a corticoterapia imunossupressora satisfatoriamente, principalmente na sua fase aguda.
\end{abstract}

Palavras-chave: Canino, miopatias inflamatórias, miosite eosinofílica.

\begin{abstract}
Eosinophylic myositis is an immune-mediated muscle disease that attacks dogs characterized by production of antibodies directed against the fibers that constitute the muscle responsible for the mastication. This disorder appears in the acute and chronic forms. The acute form is more commonly found and involves pseudotrism, and can progress up to the impossibility of mouth opening. The chronic form is characterized by atrophy and necrosis of the masticatory muscles. The serum dosage of creatine kinase (CK) and the histopathologic exam of the muscle involved are important to establish the diagnosis and evaluate the efficacy in the treatment. The answer to the therapy and the prognosis are better when the disease is treated in an acute form. This article reports case of masticatory muscle myositis in a female Shar-Pei dog attended and treated in the Veterinary Hospital of the Federal University of Mato Grosso (HOVET/UFMT) for five months. CK was high and after the histopathologic exam was found coagulative necrosis, multifocal moderate muscle fibers, perivascular infiltrate composed of phagocytic cells and frequent muscle regeneration. The animal was treated with prednisone (2 mg/ $/ \mathrm{kg}$ ), once a day (SID), for 20 consecutive days and presented a considerable improvement. It is concluded that the masticatory muscle myositis of the animal in question is an immunological disease that responds satisfactorily to immunosuppressive corticotherapy, mainly in its acute phase.
\end{abstract}

Keywords: Canine, inflammatory myopathies, eosinophilic myositis.

\section{Introdução}

Miosite mastigatória é um distúrbio imunomediado caracterizado pela produção de anticorpos direcionados contra as fibras tipo 2M que constituem músculos responsáveis pela mastigação, possível motivo que limita a doença apenas a estes músculos (Lemos et al., 2007). A doença é comum em cães, entretanto, há poucos relatos de ocorrência no Brasil. Acomete qualquer raça, principalmente cães de grande porte, sem predileção por sexo e idade, porém, jovens são mais acometidos. Apresenta- se nas formas aguda ou crônica. A forma aguda ou miosite eosinofílica caracteriza-se por edema recidivante dos músculos mastigatórios e dor ao manipular a mandíbula (Costa et al., 2005), disfagia, sialorreia e linfadenopatia submandibular e préescapular (Fioravante et al., 2004). Impossibilidade em abrir a boca mesmo em plano anestésico profundo é um achado clínico importante (Shelton, 2006). A forma crônica caracteriza-se pela atrofia progressiva, bilateral e simétrica dos músculos masseter, temporal e pterigoides (Costa et al., 2005).

\footnotetext{
* Discente, Curso de Graduação em Medicina Veterinária, Faculdade de Agronomia, Medicina Veterinária e Zootecnia (FAMEVZ) -UFMT, Cuiabá, Mato Grosso - Brasil. E-mail: thaly.prii@hotmail.com

** Departamento de Clínica Médica Veterinária, HOVET-UFMT, Cuiabá, MT, Brasil.

*** Residente no Setor de Diagnóstico por Imagem, HOVET-UFMT.

**** Professor Adjunto de Medicina Veterinária, UFFS, Realeza, PR, Brasil.

***** Professor Adjunto de Medicina Veterinária, UFMT, Cuiabá, MT, Brasil.
} 
O diagnóstico baseia-se na anamnese, sinais clínicos e biópsia do músculo comprometido (Taylor, 2006). Há anemia discreta, leucocitose neutrofílica e ocasionalmente eosinofilia periférica (Fioravante et al., 2004). A atividade sérica de creatina quinase (CK) apresenta-se normal ou pouco elevada. Microscopicamente nos casos agudos há necrose muscular, infiltrado perivascular de células inflamatórias e regeneração muscular. A fase crônica caracteriza-se por severa atrofia, desaparecimento de fibras musculares, infiltrado multifocal de células inflamatórias e deposição de colágeno na musculatura (Costa et al., 2005).

A terapia é à base de doses imunossupressoras de corticosteroides, sendo sugerido o uso de um a dois $\mathrm{mg} / \mathrm{kg}$ de prednisona, VO, a cada 12 horas, até que a CK e a função mastigatória se normalizem (Fioravante et al., 2004; Dewey, 2005). Taylor (2006) indica o uso da terapia por três semanas, com redução da dose para um $\mathrm{mg} / \mathrm{kg}$ a cada 24 horas e então reduzida gradualmente em quatro a seis meses até $0,5 \mathrm{mg} / \mathrm{kg}$, em dias alternados. Através da concentração sérica de CK e da capacidade de abrir a boca, determina-se a resposta à terapia. Casos na fase aguda respondem melhor à corticoterapia (Costa et al., 2005).

Neste trabalho relatam-se os achados clínicos, patológicos e resposta ao tratamento em um cão da raça Shar-Pei, atendido e tratado no HOVET-UFMT com miosite dos músculos mastigatórios.

\section{Relato do caso}

Atendeu-se, no Hospital Veterinário da Universidade Federal de Mato Grosso - HOVET/UFMT um canino, fêmea, da raça Shar-Pei, de três anos de idade, pesando $17,2 \mathrm{~kg}$, com a queixa principal de estar com dificuldade para abrir a boca há três meses. Ao exame físico, a temperatura corporal, mucosas, frequências cardíaca e respiratória e o estado de hidratação estavam dentro dos padrões de referência. Os linfonodos submandibulares, inguinais e poplíteos apresentavam-se aumentados. Alimentava-se por sucção de alimentos pastosos e líquidos como ração úmida, leite e iogurtes. A atrofia da musculatura da face era visualmente notável e à palpação o animal apresentava sensibilidade dolorosa. Requisitou-se hemograma completo, bioquímica sérica: ureia, creatinina, alanina aminotransferase (ALT), fosfatase alcalina (FA), creatina quinase (CK) e aspartato aminotrasferase (AST), e biópsia do músculo masseter para exame histopatológico. Para a realização da biópsia o cão foi submetido à anestesia geral, realizada através da indução com propofol $(4 \mathrm{mg} / \mathrm{kg})$ pela via intravenosa, e manutenção com pequenas doses $(1 \mathrm{ml})$ do mesmo fármaco. Por ser uma técnica bastante invasiva, optouse pela biópsia unilateral do lado direito de forma profunda com «punch» de biópsia de cinco $\mathrm{mm}$, após a abertura de um $\mathrm{cm}$ de pele e subcutâneo sobre o músculo masseter, sendo esta área previamente preparada com tricotomia e antissepsia. Após a remoção do fragmento muscular, suturou-se a pele com fio de náilon monofilamentoso 3-0 e padrão isolado simples. Durante o plano anestésico notou-se dificuldade para ampliar o ângulo da mandíbula, sendo que a abertura da boca, medida do dente canino superior ao canino inferior foi de dois $\mathrm{cm}$.

No hemograma as alterações restringiam-se a série branca, com leucocitose por neutrofilia e discreta eosinofilia periférica. $\mathrm{Na}$ bioquímica sérica, a ureia estava abaixo de seu valor de referência $(13,0 \mathrm{mg} / \mathrm{dL})$. A CK apresentava-se extremamente acima de seu valor de referência $(2.496,6 \mathrm{UI} / \mathrm{L})$ e as concentrações séricas de ALT e AST estavam normais (28 UI/L e $11 \mathrm{UI} / \mathrm{L}$, respectivamente).

Microscopicamente, no músculo masseter foram observadas compatíveis alterações compatíveis com quadro agudo de miosite dos músculos mastigatórios (Figura 1).

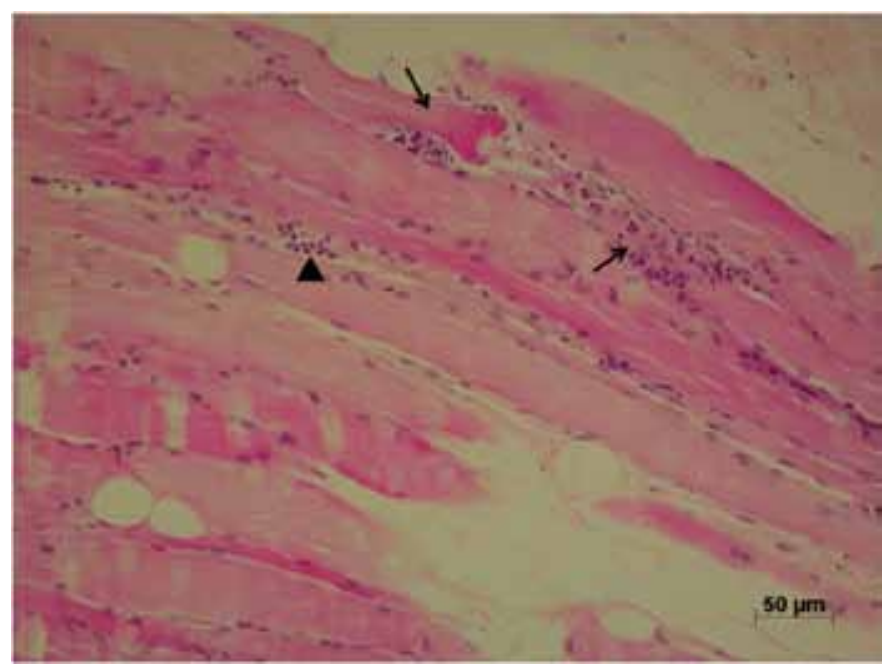

Figura 1: Biópsia do músculo masseter de um canino da raça Shar-Pei fêmea de três anos de idade, com miosite dos músculos mastigatórios, estágio agudo. Há necrose coagulativa segmentar de fibras musculares (setas), caracterizada por picnose nuclear e tumefação, eosinofilia, floculação e vacuolização do citoplasma. Há também infiltrado multifocal moderado de células mononucleares (triângulo) - HE.

A terapia imunossupressora foi instituída utilizando-se prednisona na dose de dois $\mathrm{mg} / \mathrm{kg}$, uma vez ao dia, durante 20 dias consecutivos e omeprazol um $\mathrm{mg} / \mathrm{kg}$ SID durante o tempo de tratamento com o corticoide. Após quatro dias de tratamento, a proprietária relatou que o cão começou a expor a língua e após 20 dias, já se lambia e latia, mas havia dificuldades em abrir a boca. A abertura bucal já era de cinco cm (Figura 2). Foi coletada nova amostra de sangue para hemograma e bioquímica sérica notando-se discreta anemia, causada por uma leve redução dos valores do hematócrito e da hemoglobina. A atividade sérica de CK ainda estava acima das concentrações normais (625,0 UI/L). Foi reduzida a dose de glicocorticoide para um mg/kg SID por 15 dias consecutivos, manteve-se a prescrição de omeprazol por mais 15 dias.

No retorno seguinte, cinco meses após o início do tratamento, o animal havia ganhado peso $(5,100 \mathrm{~kg})$ e não se notava evidência de atrofia dos músculos mastigatórios, sendo que, segundo a proprietária, após 70 dias do início do tratamento a cadela conseguia se alimentar, lamber-se, latir e bocejar normalmente. Para evitar recidiva, a prednisona foi prescrita na dose de 0,5 $\mathrm{mg} / \mathrm{kg}$ SID durante 15 dias e após esse período essa dose foi administrada em dias alternados. O uso do omeprazol foi suspenso. Coletou-se nova amostra de sangue para hemograma e análise sérica de CK. Ao hemograma foi encontrada discreta neutrofilia $\left(13,7 \times 10^{3} / \mathrm{mm}^{3}\right)$ e linfopenia $\left(0,4 \times 10^{3} / \mathrm{mm}^{3}\right)$. A CK apresentou-se dentro de seus valores de referência (141,0 UI/L).

Após três meses e meio seguindo a última prescrição, diagnosticou-se gestação de 45 dias, interrompendo-se o tratamento. Nasceram seis filhotes saudáveis, e até então a paciente não apresentou recidiva. 

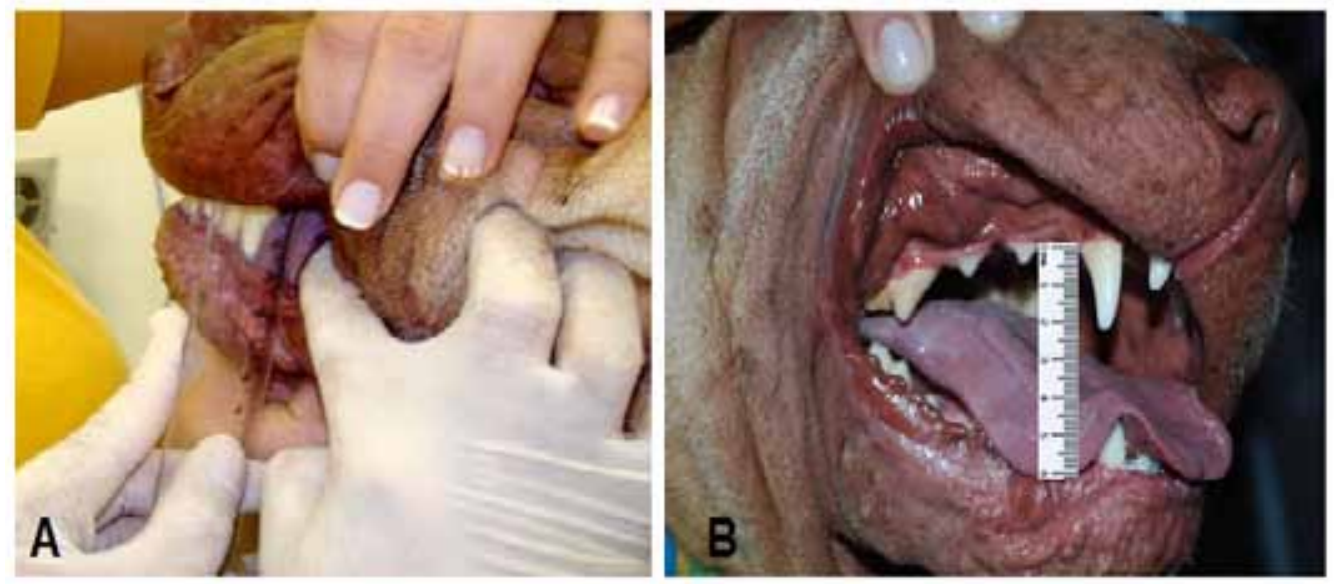

Figura 2: Canina fêmea da raça Shar-Pei com pseudotrismo, por miosite dos músculos mastigatórios. A - Antes do tratamento, a amplitude bucal do dente canino superior ao dente canino inferior media aproximadamente dois $\mathrm{cm}$. B Após 20 dias de tratamento, a abertura da boca apresentava-se maior que cinco $\mathrm{cm}$.

\section{Discussão e conclusões}

Como descrito por Costa et al. (2005), a miosite dos músculos mastigatórios é uma doença pouco frequente na clínica de pequenos animais. Por este motivo, durante a anamnese o clínico veterinário deve manter-se atento às informações relatadas pelo proprietário e sempre observar as alterações encontradas no animal durante o exame físico.

A análise histológica foi a principal técnica usada para caracterização diagnóstica neste caso, observando-se necrose coagulativa de músculos mastigatórios associado com inflamação, achado similar ao descrito por Fioravanti et al. (2004), Costa et al., (2005) e Taylor (2006). Adicionalmente, foram achados complementares ao diagnóstico a leucocitose com neutrofilia e eosinofilia periférica. Fioravanti et al., (2004) e Taylor (2006) ainda ressaltam que no hemograma ocorre anemia discreta. Costa et al., (2005) citam que a atividade sérica de CK e AST estão normais ou ligeiramente elevados. Neste caso, a atividade de CK estava aproximadamente dez vezes maior (2.496,6 UI/L) e AST estava dentro do parâmetro normal.

O uso de omeprazol fez-se necessário para minimizar a possibilidade de gastrite medicamentosa, devido aos efeitos colaterais do uso do corticoide (Andrade e Camargo, 2002), 2002), a qual se recomenda uso em doses imunodepressivas conforme sugestão de Fioravanti et al., (2004), Dewey (2005)

\section{Referências}

ANDRADE S.F.; CAMARGO M.M. Terapêutica do sistema digestivo - Drogas utilizadas no sistema digestivo de animais de pequeno porte. In: ANDRADE, S. F. Manual de Terapêutica Veterinária, 2. ed, São Paulo: Roca, 2002, p. 223-246.

AZEVEDO, J.S.; SANTOS, L.P; THOMÉ, S.; WICKERT, A.P. Diagnóstico de miosite dos músculos mastigatórios em um canino - relato de caso. In: Congresso Brasileiro de Medicina Veterinária - CONBRAVET, 35., 2008. Gramado,RS.

BLOT, S. Distúrbios dos músculos esqueléticos. In: ETTINGER, S.J.; FELDMAN, E.C. Tratado de Medicina Interna Veterinária. $5^{\text {a }}$ ed. Rio de Janeiro: vol.1; Guanabara, 2004, p. 723-729.

COSTA, P. R. S.; CONCEIÇÃO, L. G.; PARZANINI, G. R. Miosite mastigatória em cão: relato de caso. In: Clínica Veterinária. São Paulo, n. 56, p. 42-46, 2005. e Taylor (2006). Taylor (2006) indica o uso da terapia por três semanas, quando a dose pode ser reduzida à metade da inicial, administrada a cada 24 horas e então reduzida gradualmente em quatro a seis meses até chegar à menor dose possível de $0,5 \mathrm{mg} / \mathrm{kg}$, em dias alternados. Após 70 dias de tratamento foi realizada nova coleta de amostra de sangue para análise da concentração sérica de CK, que se apresentava dentro dos parâmetros normais para a espécie (141,0 UI/L). Esta avaliação foi usada como parâmetro para redução gradual da administração de prednisona.

Não ocorreu recidiva nestes seis meses de análise, após a interrupção do tratamento ocasionada pela gestação, e também se notou que os filhotes nasceram saudáveis. Durante a gestação a dose administrada de prednisona foi de $0,5 \mathrm{mg} /$ $\mathrm{kg}$ em dias alternados. Costa et al. (2005) afirmam que há uma boa resposta à corticoterapia e o prognóstico é bom quando a doença é identificada e tratada durante a sua fase aguda.

O diagnóstico da miosite dos músculos mastigatórios se baseia no resultado de exames laboratoriais, como a análise sérica da enzima creatina quinase e o exame histopatológico do músculo envolvido. Tais exames também corroboram o sucesso ou fracasso da terapia medicamentosa, que quando instituída na fase aguda da doença apresenta prognóstico favorável. Por este fator, o diagnóstico deve ser estabelecido o mais rápido possível, a fim de que a terapia apresente os resultados desejados.

DEWEY, C.W. Disorders of the Peripheral Nervous System. In: Congresso Nazionale Multisala SCIVAC, 50. 2005. Rimini, Itália.

FIORAVANTI, M.C.S.; OLIVEIRA, K.S.; MENEZES, L.B.; JULIANO, R.S. Doenças da Cavidade Oral. In: ROZA, M.R. Odontologia em Pequenos Animais. Rio de Janeiro: L.F. Livros de Veterinária, 2004, p. 253-277.

LEMOS, M.G.; CARTANA, C.B.; GUIM, T.N.; BERGMANN, L.K.; MUELLER, E.N.; WILHELM, G.; PEREIRA, I.C.; GUIM, T.N.; NOBRE, M.O. Miosite mastigatória - relato de um caso. In: XVI Congresso de Iniciação Científica - CIC. 2007. Pelotas, RS.

SHELTON, G.D. Immune-mediated muscle diseases: myasthenia gravis and inflammatory myopathies. In: ESVOT Congress Munich, 13. 2006. Munich, Alemanha.

TAYLOR, S.M. Distúrbios Neuromusculares. In: NELSON R.W.; COUTO C.G. Medicina Interna de Pequenos Animais. Rio de Janeiro: Elsevier, $3^{a}$ ed., p. 1027-1036, 2006. 